\title{
Levantamento do impacto causado pela construção da Usina Hidrelétrica de Paraibuna
}

\author{
Suely Franco Siqueira Lima ${ }^{1}$ \\ Getulio Teixeira Batista ${ }^{2}$ \\ ${ }^{1}$ Instituto Nacional de Pesquisas Espaciais (INPE) \\ Av. dos Astronautas, 1758 - Jd. da Granja \\ Caixa Postal 515 - 12201-970 - São José dos Campos - SP, Brasil \\ Telefone: (12) 39456428 \\ suely@dsr.inpe.br \\ ${ }^{2}$ Universidade de Taubaté (UNITAU) \\ Programa de Pós-Graduação em Ciências Ambientais \\ Estrada Mun. Dr. José Luiz Cembranelli, 5.000 - Bairro Itaim \\ CEP 12.081-010 - Taubaté, SP, Brasil \\ Tel. (12) 3625-4116 / Fax (12) 3632-8956 \\ getulio@agro.unitau.com.br
}

\begin{abstract}
Environmental education treated with concepts only, without a spatial and temporal perception of the environment doesn't effectively make students to understand environmental problems. Current basic education programs lack resources to make possible temporal and spatial analysis of the local and global problems. In this sense, this work demonstrated the possibility of geotecnology use to assist Basic Education programs by developing a didactic material based on free available geotecnology systems, using the case study of the Paraibuna Hydroelectric Power Station reservoir. Environmental changes caused by the construction of the hydroelectric power reservoir were mapped based on CBERS and Landsat imagery using the SPRING software package. The charts, cadastral maps and the entire georeferenced database containing information on the environmental impacts were made available in a DVD which contains a tutorial of basic notions of Remote Sensing and step by step instructions on how the educator's and student's can interact with this database.
\end{abstract}

Keywords: Geotecnology; education; environment, reservoir, GIS.

\section{Introdução}

A bacia do rio Paraíba do Sul localiza-se na região sudeste do Brasil e ocupa uma área de aproximadamente $56.600 \mathrm{~km}^{2}$ que envolve três dos mais desenvolvidos Estados: São Paulo $\left(13.500 \mathrm{~km}^{2}\right)$, Minas Gerais $\left(20.500 \mathrm{~km}^{2}\right)$ e Rio de Janeiro $\left(22.600 \mathrm{~km}^{2}\right)$. O rio Paraíba do Sul é formado pela confluência dos rios Paraitinga e Paraibuna e deságua no norte fluminense, no município de São João da Barra, percorrendo uma extensão aproximada de 1.150 km (IEPA, 2007). A Bacia abrange 180 municípios, sendo: 88 em Minas Gerais, 53 no Estado do Rio e 39 no estado de São Paulo, com uma população total de 5.6 milhões de pessoas (SERRICHO et al., 2006) que dependem de suas águas, sem mencionar a população do Rio de Janeiro que abastece de suas águas pela transposição para o rio Guandu (CAMPOS, 2007). Desta forma, o mapeamento e a implementação de uma base de informações georreferenciadas permitem integrar, atualizar, e analisar as condições ambientais de bacias hidrográficas de forma rápida e eficiente para a tomada de decisões político-administrativas.

Uma bacia do porte da do Paraíba do Sul tem grande diversidade de ambientes e vem sofrendo ao longo dos anos diversas modificações de origem antrópica. Uma das grandes intervenções tem sido a construção de barragens para regularização de vazão e geração de energia elétrica. Nesse contexto, esse artigo apresenta um levantamento do impacto causado pela construção da Usina Hidrelétrica de Paraibuna, apresentado de forma didática, com 
informações disponibilizadas em DVD, constituindo um material didático para ser usado na Educação Básica, com base em geotecnologias disponíveis, que possibilitam ao educando uma visão espacial e temporal dos problemas ambientais de forma contextualizada e com ênfase na conservação de recursos hídricos, por meio do levantamento do impacto ambiental causado por usinas hidrelétricas no rio Paraíba do Sul. Dessa forma, foram elaborados mapas temáticos que evidenciam as mudanças de uso e ocupação do solo decorrentes da implantação da Hidrelétrica de Paraibuna no período 1973 a 2004, integrados em um banco de dados contendo aspectos legais ligados à construção e manutenção de hidrelétricas.

A relevância desse trabalho está em disponibilizar dados da bacia hidrográfica do rio Paraíba do Sul e demonstrar a possibilidade do uso da geotecnologia como recurso que permite uma visualização temporal e espacial do ambiente para orientar ações para formação de opinião em alunos do ensino fundamental para que eles possam contribuir de modo preventivo na preservação do rio do rio Paraíba do Sul. Ressalta-se que toda tecnologia e dados utilizados são disponíveis sem custos.

\section{Materiais e Método}

- Construção do banco de dados das hidrelétricas do rio Paraíba do Sul com base no aplicativo SPRING 4.3 e imagens do satélite CBERS-2, sensor CCD com datas de 2004, 2005 e 2006.

- Mapeamento das mudanças ambientais provocadas pela implementação da Hidrelétrica de Paraibuna no período 1973 a 2004 com base nas imagens do satélite Landsat adquiridas nas datas de 1973, 1986 e 1999.

- Construção de banco de dados com legislação relacionada à construção e manutenção de hidrelétrica e análise do cumprimento das mesmas.

- Elaboração do material didático.

\section{Resultados}

\subsection{Construção do banco de dados das hidrelétricas do rio Paraíba do Sul}

Para a construção do banco de dados foi selecionado o aplicativo SPRING 4.3 por ser de acesso livre e analisada a área correspondente a um retângulo que envolve a represa com coordenadas geográficas long. 1: $47^{\circ} 39^{`} 51.37^{\prime} \mathrm{W}$, lat.1: $25^{\circ} 31^{`} 24.56^{\prime} \mathrm{S}$; long. 2 : $39^{\circ} 13^{\prime}$ $7.61^{\prime \prime} \mathrm{W}$ e lat. 2: $19^{\circ} 26^{`} 0.58^{\prime \prime} \mathrm{S}$. Inicialmente, foi construído o mosaico das imagens ao longo do percurso do rio Paraíba do Sul. As imagens utilizadas do satélite CBERS-2, sensor CCD foram das datas de 2004, 2005 e 2006, no qual foram sobrepostos mapas com a delimitação e identificação dos estados e respectivas tabelas de seus atributos (Figura 1); assim como, foram identificadas as hidrelétricas ao longo do percurso do rio Paraíba do Sul e suas tabelas de atributos (Figura 2). Para melhor identificar o percurso do rio, foi sobreposto também o seu traçado, resultante da interpretação visual das imagens utilizadas. 


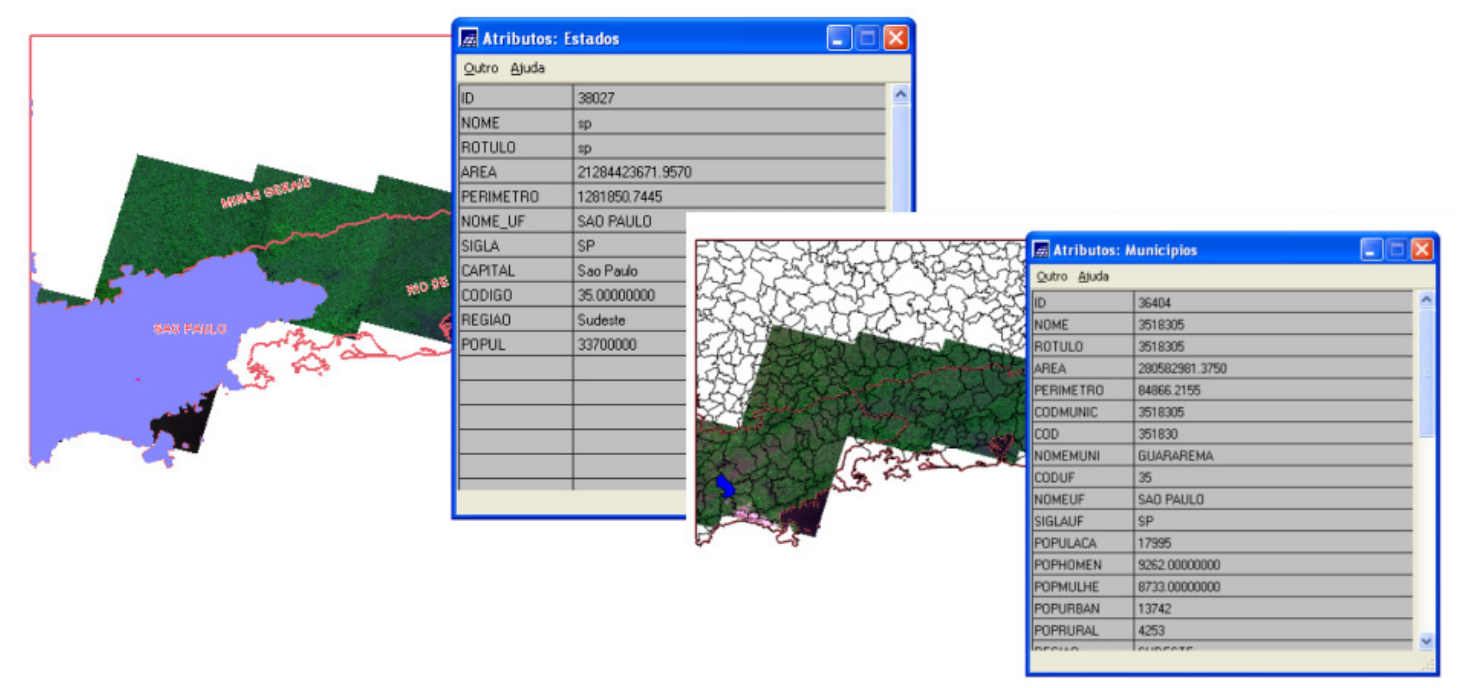

Figura 1. Identificação do Estado de São Paulo (azul claro) e do município de Guararema (azul escuro) e consulta às respectivas tabelas de atributos para exemplificar uma consulta ao banco de dados que contém os estados e municípios que compõem a bacia do rio Paraíba do Sul delimitados sobre o mosaico formado a partir de oito imagens CBERS de 2004, 2005 e 2006.

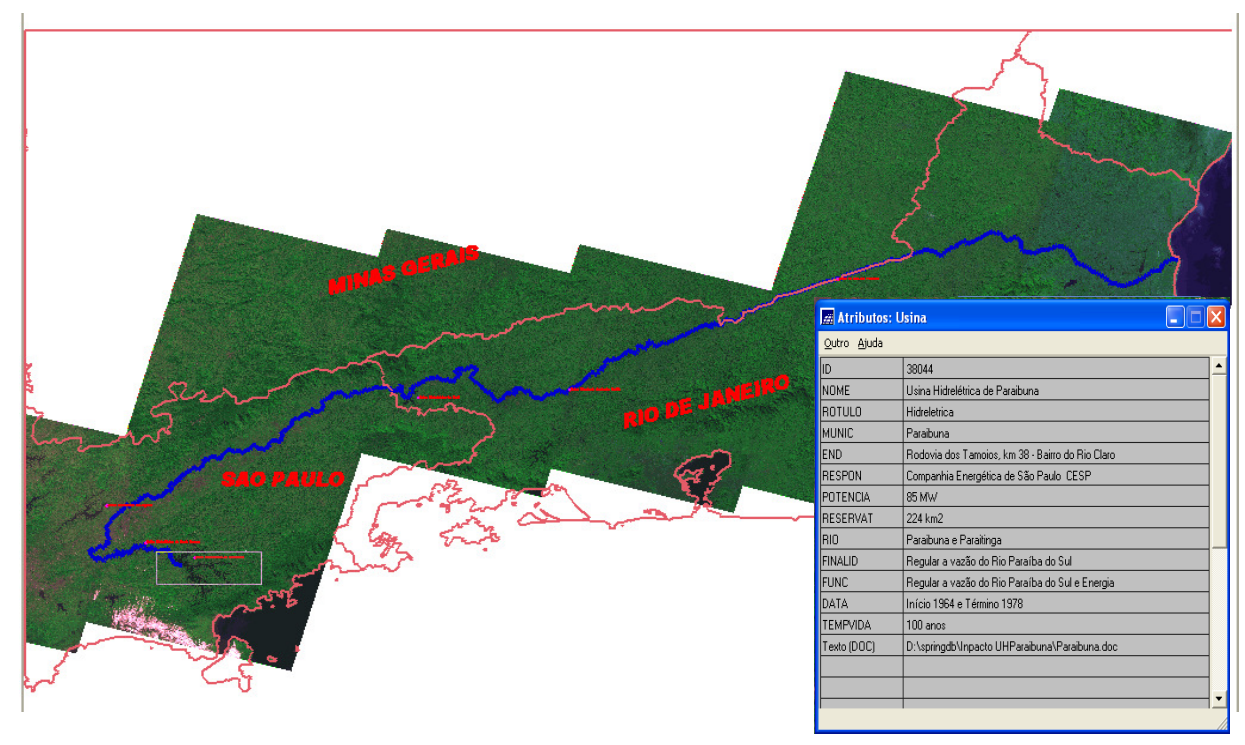

Figura 2. Identificação espacial do percurso do rio Paraíba do Sul e das usinas hidrelétricas (em letras menores) e consulta à tabela de atributos da Usina Hidrelétrica de Paraibuna.

As tabelas de atributos das hidrelétricas trazem as informações apresentadas na Tabela 1. 
Tabela 1. Atributos e parâmetros das Usinas Hidrelétricas do percurso do rio Paraíba do Sul.

\begin{tabular}{|c|c|c|c|c|c|c|}
\hline Atributo & \multicolumn{6}{|c|}{ USINAS HIDRELÉTRICAS } \\
\hline Nome & $\begin{array}{l}\text { Usina } \\
\text { Hidrelétrica } \\
\text { Paraibuna }\end{array}$ & $\begin{array}{c}\text { Usina } \\
\text { Hidrelétrica de } \\
\text { Santa Branca }\end{array}$ & $\begin{array}{c}\text { Usina } \\
\text { Hidrelétrica de } \\
\text { Jaguari }\end{array}$ & $\begin{array}{c}\text { Usina } \\
\text { Hidrelétrica de } \\
\text { Funil }\end{array}$ & $\begin{array}{c}\text { Usina } \\
\text { Elevatória de } \\
\text { Santa Cecília }\end{array}$ & $\begin{array}{l}\text { Usina de } \\
\text { Ilha dos } \\
\text { Pombos }\end{array}$ \\
\hline Município & $\begin{array}{l}\text { Paraibuna } \\
\text { SP }\end{array}$ & $\begin{array}{c}\text { Santa Branca } \\
\text { SP }\end{array}$ & $\begin{array}{l}\text { São José dos } \\
\text { Campos - SP }\end{array}$ & $\begin{array}{l}\text { Itatiaia } \\
\text { RJ }\end{array}$ & $\begin{array}{l}\text { Barra do } \\
\text { Piraí- RJ }\end{array}$ & $\begin{array}{l}\text { Carmo } \\
\text { RJ }\end{array}$ \\
\hline Endereço & $\begin{array}{c}\text { Rodovia dos } \\
\text { Tamoios, km } \\
38 \text { - Bairro } \\
\text { do Rio Claro }\end{array}$ & $\begin{array}{l}\text { Bairro Angola } \\
\text { acesso Rodovia } \\
\text { Nilo Máximo, } \\
\text { Km } 11\end{array}$ & $\begin{array}{l}\text { Estrada do } \\
\text { Pagador } \\
\text { Andrade km } 14 \\
\text { - Bairro do } \\
\text { Pagador de } \\
\text { Andrade }\end{array}$ & $\begin{array}{l}\text { Rodovia } \\
\text { Presidente } \\
\text { Dutra. Km } 318\end{array}$ & $\begin{array}{l}\text { Rua Assis } \\
\text { Ribeiro } \\
\text { Bairro } \\
\text { Centro }\end{array}$ & $\begin{array}{l}1^{0} \text {. Distrito } \\
\text { Porto } \\
\text { Velho do } \\
\text { Cunha. }\end{array}$ \\
\hline $\begin{array}{c}\text { Data de } \\
\text { construção }\end{array}$ & $\begin{array}{c}\text { Início } 1964 \text { e } \\
\text { Término } \\
1978\end{array}$ & $\begin{array}{l}\text { Início } 1957 \text { e } \\
\text { Término } 1961\end{array}$ & $\begin{array}{l}\text { Início } 1963 \text { e } \\
\text { Término } 1971\end{array}$ & $\begin{array}{c}\text { Início } 1961 \text { e } \\
\text { Término } 1969\end{array}$ & $\begin{array}{c}\text { Início } 1920 \mathrm{e} \\
\text { Término } \\
1952\end{array}$ & $\begin{array}{c}\text { Início } 1920 \\
\text { e Término } \\
1924\end{array}$ \\
\hline $\begin{array}{l}\text { Potência } \\
\text { Energética }\end{array}$ & $85 \mathrm{MW}$ & $56 \mathrm{MW}$ & 27,6 MW & $216 \mathrm{MW}$ & 36,8 MVA & $186 \mathrm{MW}$ \\
\hline Transposição & - & - & - & - & $160 \mathrm{~m} 3 / \mathrm{s}$ & - \\
\hline $\begin{array}{l}\text { Área do } \\
\text { reservatório }\end{array}$ & $224 \mathrm{~km}^{2}$ & $27,5 \mathrm{~km}^{2}$ & $56 \mathrm{~km}^{2}$ & $40 \mathrm{~km}^{2}$ & $2,7 \mathrm{Km}^{2}$ & $4,26 \mathrm{Km}^{2}$ \\
\hline Rios & $\begin{array}{l}\text { Paraibuna e } \\
\text { Paraitinga }\end{array}$ & Paraíba do Sul & Jaguari & Paraíba do Sul & $\begin{array}{l}\text { Paraíba do } \\
\quad \text { Sul }\end{array}$ & $\begin{array}{c}\text { Paraíba do } \\
\text { Sul }\end{array}$ \\
\hline Responsável & $\begin{array}{c}\text { Companhia } \\
\text { Energética } \\
\text { de São Paulo } \\
\text { CESP }\end{array}$ & $\begin{array}{l}\text { LIGHT Energia } \\
\text { S/A }\end{array}$ & $\begin{array}{l}\text { Companhia } \\
\text { Energética de } \\
\text { São Paulo - } \\
\text { CESP }\end{array}$ & $\begin{array}{l}\text { FURNAS - } \\
\text { Centrais } \\
\text { Elétricas S.A. }\end{array}$ & $\begin{array}{c}\text { LIGHT } \\
\text { Energia S/A }\end{array}$ & $\begin{array}{l}\text { LIGHT } \\
\text { Energia } \\
\text { S/A }\end{array}$ \\
\hline $\begin{array}{l}\text { Motivo de } \\
\text { sua } \\
\text { construção }\end{array}$ & $\begin{array}{l}\text { Regular a } \\
\text { vazão do rio } \\
\text { Paraíba do } \\
\text { Sul }\end{array}$ & $\begin{array}{c}\text { Regular a vazão } \\
\text { do rio Paraíba } \\
\text { do Sul }\end{array}$ & $\begin{array}{c}\text { Regular a vazão } \\
\text { do rio Paraíba } \\
\text { do Sul e } \\
\text { Abastecimento }\end{array}$ & $\begin{array}{l}\text { Eletrificação de } \\
\text { uma estrada } \\
\text { de ferro }\end{array}$ & Energia & Energia \\
\hline Função & $\begin{array}{c}\text { Regular a } \\
\text { vazão do rio } \\
\text { Paraíba do } \\
\text { Sul e Energia }\end{array}$ & $\begin{array}{c}\text { Regular a vazão } \\
\text { do rio Paraíba } \\
\text { do Sul e } \\
\text { Energia }\end{array}$ & $\begin{array}{c}\text { Regular a vazão } \\
\text { do rio Paraíba } \\
\text { do Sul, } \\
\text { Abastecimento } \\
\text { e Energia }\end{array}$ & $\begin{array}{c}\text { Regular a vazão } \\
\text { do rio Paraíba } \\
\text { do Sul, } \\
\text { Abastecimento } \\
\text { e Energia }\end{array}$ & $\begin{array}{l}\text { Abastecimen } \\
\text { to d`água a } \\
\text { região } \\
\text { metropolitan } \\
\text { a do rio de } \\
\text { Janeiro e } \\
\text { Energia }\end{array}$ & Energia \\
\hline $\begin{array}{l}\text { Tempo de } \\
\text { vida útil } \\
\text { estimado }\end{array}$ & 100 anos & 50 anos & 50 anos & 80 anos & 100 anos & $\begin{array}{c}\text { Usina a Fio } \\
\text { D`água }\end{array}$ \\
\hline
\end{tabular}

Fonte: AGEVAP (2006).

\subsection{Mapeamento das mudanças ambientais ocorridas pela Hidrelétrica de Paraibuna}

Foi construído um mapa cadastral (mapa temático associado com tabela de atributos para cada classe mapeada) com a identificação dos municípios com áreas parcialmente inundadas pelo reservatório da hidrelétrica de Paraibuna. As tabelas de atributos trazem informações (CESP, 1995) e fotografias que ajudam a evidenciar as mudanças territoriais, populacionais, econômicas e históricas como mostrados na Tabela 2 e na Figura 3. 
Tabela 2. Atributos dos municípios parcialmente inundados pela represa de Paraibuna.

\begin{tabular}{|l|c|c|c|}
\hline \multicolumn{1}{|c|}{ Atributos } & \multicolumn{3}{|c|}{ Municípios } \\
\hline & Paraibuna & Redenção da Serra & Natividade da Serra \\
\hline População em 1960 & 15.105 & 5.326 & - \\
\hline População em 1970 & 13.845 & 5.135 & 10.000 \\
\hline População em 1980 & 14.114 & 3.970 & - \\
\hline População em 1995 & - & - & 6.500 \\
\hline População em 2007 & 18.574 & 4.076 & 7.313 \\
\hline Área total do município & $810 \mathrm{Km}^{2}$ & $309 \mathrm{Km}^{2}$ & $833 \mathrm{Km}^{2}$ \\
\hline Área Inundada & $70 \mathrm{Km}^{2}$ & $20 \mathrm{Km}^{2}$ & $120 \mathrm{Km}^{2}$ \\
\hline Economia em 1960 & Produção de leite & Agropecuária & Agropecuária \\
\hline Economia em 1965 & Construção da UH & Agropecuária & Agropecuária \\
\hline \multirow{2}{*}{ Economia em 2007 } & Agricultura & Açúcar \\
& Pecuária & $\begin{array}{c}\text { Mandioca } \\
\text { Turismo } \\
\text { levinocultura de e corte }\end{array}$ & $\begin{array}{c}\text { Agropecuária } \\
\text { Turismo } \\
\text { Piscicultura }\end{array}$ \\
\hline
\end{tabular}

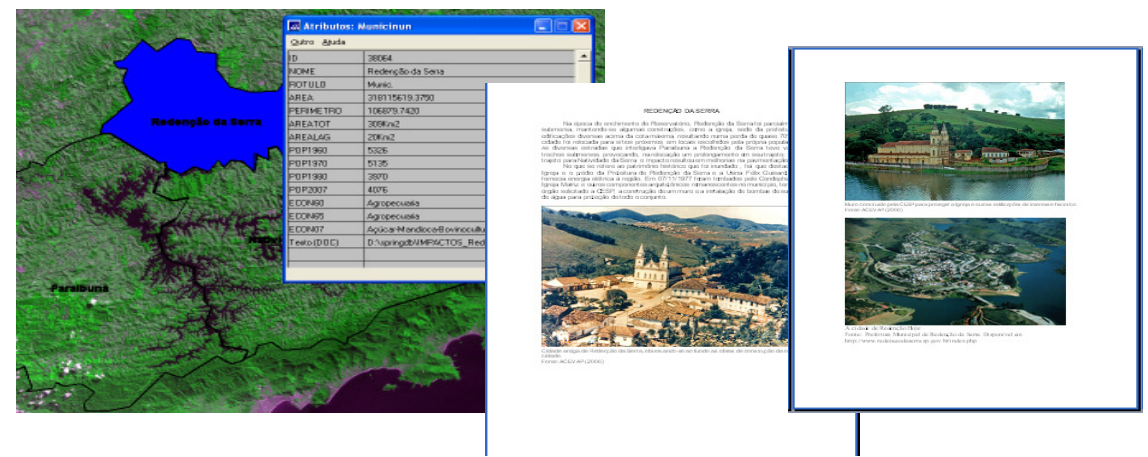

Figura 3. Detalhe do mapa temático cadastral com a identificação do município de Redenção da Serra que foi parcialmente inundado pelo reservatório de Paraibuna e consulta à sua respectiva tabela de atributos obtidos diretamente da tela do SPRING.

Foram gerados mapas temáticos sobre o uso e ocupação do solo obtidos a partir da classificação supervisionada das imagens CBERS de 2004 e das imagens do satélite Landsat das datas de 1973, 1986 e 1999 utilizando o algoritmo de classificação MAXVER (Logan et al., 1997) dentro dos limites dos municípios inundados. Dessa forma, foram gerados dezesseis mapas temáticos com as classes matas nativas, reflorestamento, água e área urbana, cobrindo um intervalo de trinta e um anos (1973 a 2004). A Figura 4 mostra um exemplo de um desses mapas.

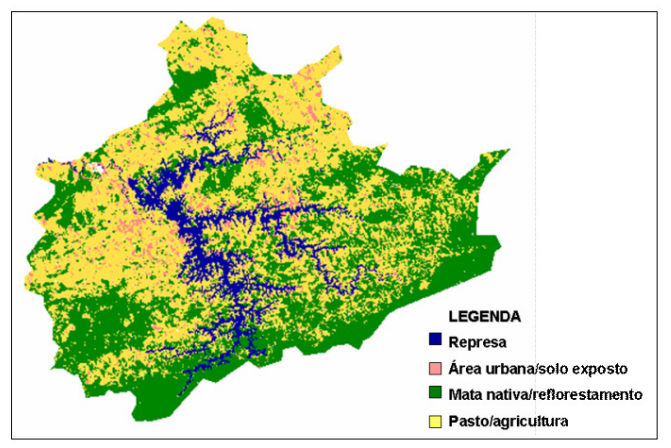

Figura 4. Mapa temático do ano de 1986 dos municípios que foram parcialmente inundados pelo reservatório de Paraibuna. 


\subsection{Banco de dados com a legislação pertinente à construção e manutenção de hidrelétrica e análise do cumprimento da mesma}

Este banco permite a visualização de forma espacial das seguintes leis: Lei 11.428/06, Lei 4771/65 e as Resoluções CONAMA 001/86 e 302/2002. Para cada um dos Planos de Informação correspondentes às essas leis, estão vinculados mapas como, exemplificado, na Figura 5 referente à Lei 11.428 (Lei da Mata Atlântica), com destaque para o texto relevante dessa lei que dispõe sobre a utilização e proteção da vegetação nativa do bioma Mata Atlântica.

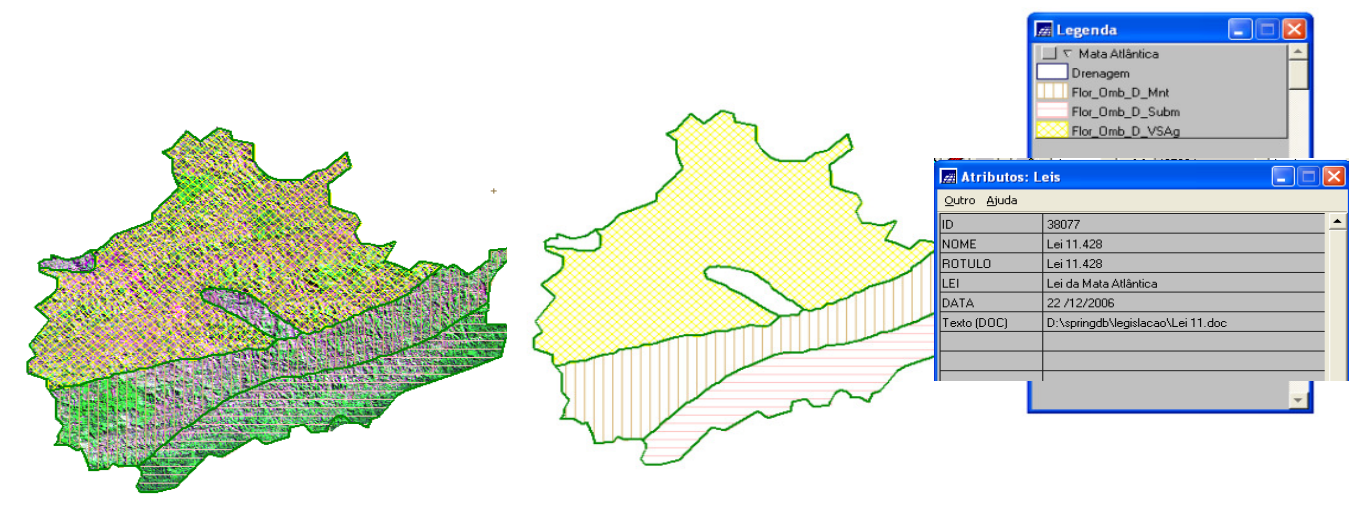

Figura 5. Exemplo de Planos de Informações referentes à Lei 11.428 de 2006 (Lei da Mata Atlântica), com as respectivas tabelas de atributos.

Para a Lei 4771/65 que instituiu o Código Florestal no que se refere às Áreas de Preservação Permanente (APP) no entorno de reservatórios, foi elaborado o mapa que contém a delimitação das APPs no entorno da represa (100 m a partir da cota mais alta), representado no PI - Lei_4771/65-APP (Figura 6).

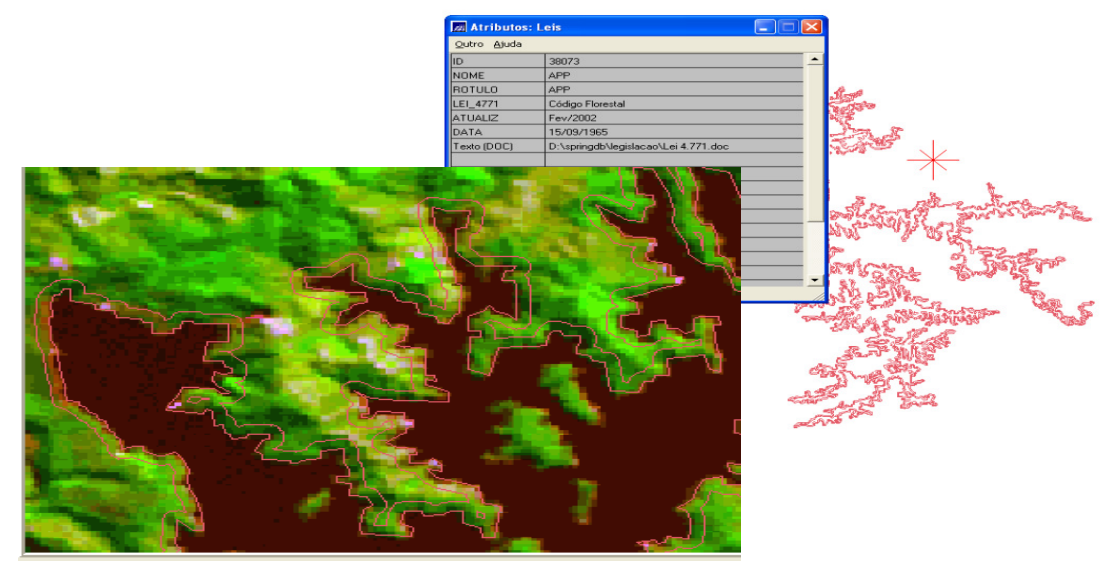

Figura 6. Exemplo dos Planos de Informações referentes à Lei 4771/65 (APP).

Foi criado o PI "Resolução CONAMA 001" para a resolução CONAMA 001/86 que trata no Artigo $2^{\circ}$ da elaboração de estudo de impacto ambiental e respectivo relatório de impacto ambiental (RIMA) a serem submetidos à aprovação do órgão estadual competente e do IBAMA para obtenção de licenciamento de atividades modificadoras do meio ambiente. 
Este PI mostra a Hidrelétrica de Paraibuna no início da construção, assim como, o trecho relevante dessa lei.

A Resolução No 302/2002 do Conselho Nacional do Meio Ambiente dispõe sobre os parâmetros, definições e limites de Áreas de Preservação Permanente (APP) de reservatórios artificiais e o regime de uso do entorno. Este PI também trás indexado o texto do trecho de interesse dessa lei e o mapa temático da ocupação na APP conforme mostra a Figura 7.

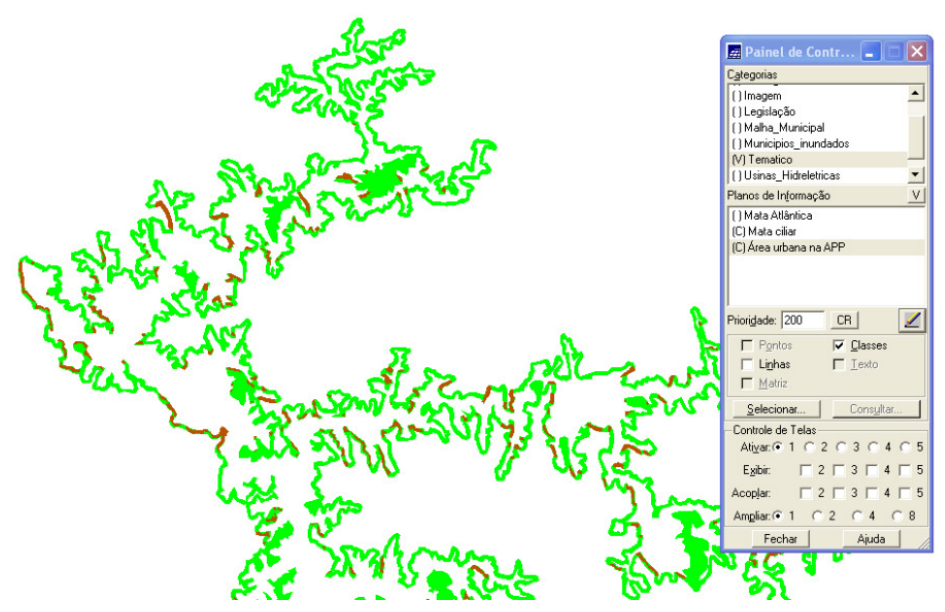

Figura 7. Exemplo de visualização do PI referente à Resolução № 302/2002.

\subsection{Elaboração do DVD com o material didático}

O material didático desenvolvido foi disponibilizado em mídia digital do tipo DVD contendo: Introdução ao diversos conceitos de Sensoriamento Remoto, de Interpretação Visual de Imagem, assim como um tutorial que demonstra passo a passo como utilizar o SPRING, especialmente, como interagir com o banco de dados "Hidrelétrica". O DVD disponibiliza ainda o instalador do SPRING (Figura 8).

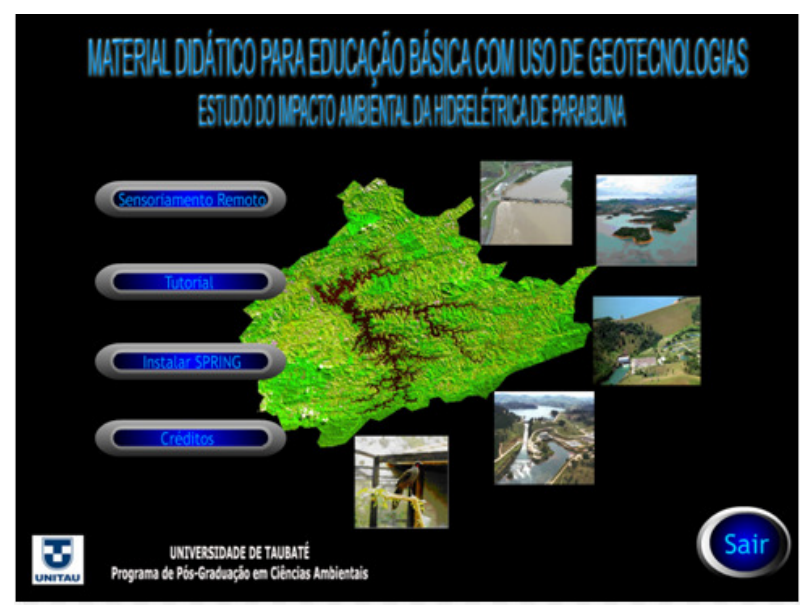

Figura 8. Portal de entrada do DVD "Material Didático para Educação Básica com Uso de Geotecnologias - Estudo do Impacto Ambiental da Hidrelétrica de Paraibuna".

Fonte: Lima e Batista (2008). 


\section{Conclusões}

Espera-se que este trabalho tenha contribuído para demonstrar as possibilidades de uso da geotecnologia para monitorar, integrar e armazenar informações para auxiliar ações de manejo, gestão e preservação de recurso hídrico. Um aspecto relevante demonstrado foi o recurso interativo para visualização temporal e espacial da dinâmica da transformação ambiental, em sistemas sujeitos a grandes impactos como a implantação de usina hidrelétrica do porte da de Paraibuna. Espera-se ainda, que os dados disponibilizados como material didático em DVD, contribuam com os educadores na tarefa de educar ambientalmente para a preservação do rio Paraíba do Sul.

\section{Referências}

AGEVAP - Associação pró-gestão das águas da Bacia Hidrográfica do rio Paraíba do Sul. Relatório da Análise dos Impactos e das Medidas Mitigadoras que envolvem a Construção e Operação de Usinas Hidrelétricas. Rio de Janeiro: Fundação COPPETEC - Laboratório de Hidrologia e Estudos de Meio Ambiente, 2006 (PSR009-R1).

CÂMARA, G.; SOUZA, R. C. M.; FREITAS, U. M.; GARRIDO, J. SPRING: Integrating remote sensing and GIS by objected-oriented data modelling. J. Computers \& Graphics, 20(3), 395-403, 1996.

CONAMA, Resolução No 001 de 23 de janeiro de 1986. Determinar à sua Secretaria Executiva que, junto a Centrais Elétricas Brasileiras S.A. - ELETROBRÁS e esta às Empresas do Sistema Elétrico, requisite as informações técnicas indispensáveis ao exame da matéria, no que concerne os estudos das alternativas e das possíveis consequiências ambientais dos projetos de construção de hidrelétricas. Diário Oficial [da] República Federativa do Brasil, Brasília, DF, 6 nov. 1986. Disponível em: <http://www.cprh.pe.gov.br>. Acesso em 02 julho 2006.

CAMPOS, J. D. Cobrança pelo uso da água: A situação da Bacia do Paraíba do Sul. 2007, 83p. <http://www.agro.unitau.br:8080/dspace/bitstream/2315/127/1/SERHIDRO-PS_2007_Palestra_Jander.pdf>.

Acesso setembro de 2009.

IEPA. Instituto Ecológico e de Proteção aos Animais (São José dos Campos, SP). Portiguara Chagas Ferreira (Cood.). A biologia e a geografia do Vale do Paraíba: trecho paulista. ISBN 978-85-61039-00-4, jun.2007.

Júlio César Assis Kuhl. A COMEPA e o Alto do Paraíba. CESP; São Paulo, 1995. 69p. (Fascículos da História da Energia Elétrica em São Paulo, $n \equiv 6)$.

Lei 11.428 - 22 de Dezembro de 2006 (Lei da Mata Atlântica). Dispõe sobre a utilização e proteção da vegetação nativa do Bioma Mata Atlântica e dá outras providências. 1294.

Lei 4.771 - 15 de Setembro de 1965 (Institui o Novo Código Florestal).

LIMA, S. F. S.; BATISTA, G. T. Estudo do Impacto Ambiental da Hidrelétrica de Paraibuna: Material Didático para Educação Básica com uso de Geoinformação. 1. ed. Taubaté: IPABHi, ISBN 978-85-6152801-0. 2008. v. 1.149 p.

LOGAN, T.; RITTER, N.; BRYANT N., 1997. Artificial neural network classification using a minimal; training set: comparison to conventional supervised classification. Photogrammetric Engineering \& Remote Sensing. v. 56, n. 4 , p. $1285-$

SERRICCHIO, C.; CALAES, V.; FORMIGA-JOHNSSON, R. M.; LIMA, A. J. R.; ANDRADE, E. de P. O CEIVAP e a gestão integrada dos recursos hídricos da bacia do rio Paraíba do Sul. Um relato da prática: Rio de Janeiro: GESTEC/CAIXA, 2005, 108p. <http://www.google.com.br/search?hl=pt-br\&client=firefoxa\&rls=org.mozilla:pt-br:official\&hs=lb1\&ei= ng3bsqeojc66laeypfmwbq\&sa=x\&oi=spell\&resnum $=0 \& c t=$ result $\& \mathrm{~cd}=1 \& \mathrm{q}=$ serricchio $+\mathrm{o}+$ ceivap $+\mathrm{e}+\mathrm{a}+\mathrm{gest} \% \mathrm{c} 3 \% \mathrm{a} 3 \mathrm{o}+\mathrm{integrada}+\mathrm{dos}+$ recursos $+\mathrm{h} \% \mathrm{c} 3 \%$ addricos $+\mathrm{da}+\mathrm{bacia}+$ do+rio+para\%c3\%adba+do+sul.\&spell=1>. Acesso em setembro de 2009. 